\title{
Erratum to: The effectiveness of apneic oxygenation during tracheal intubation in various clinical settings: a narrative review
}

\author{
David T. Wong, MD • Amanda J. Yee, BSc • Siaw May Leong, MBBS • \\ Frances Chung, MBBS, FRCPC
}

Published online: 27 February 2017

(C) Canadian Anesthesiologists' Society 2017

\section{Erratum to: Can J Anesth/J Can Anesth DOI 10.1007/s12630-016-0802-z}

In the article entitled: "The effectiveness of apneic oxygenation during tracheal intubation in various clinical settings: a narrative review" published online and in the print issue of the April 2017 issue of the Journal, Can J Anesth 2017; DOI: 10.1007/s12630-016-0802-z, the figure and legend for Figure 3 should be as seen here.

The publisher apologizes most sincerely for this error.

The online version of the original article can be found under doi:10. 1007/s12630-016-0802-z.

D. T. Wong, MD $(\bowtie) \cdot$ A. J. Yee, BSc

S. M. Leong, MBBS · F. Chung, MBBS, FRCPC

Department of Anesthesia, Toronto Western Hospital, University

Health Network, University of Toronto, MC2-405, 399 Bathurst

Street, Toronto, ON M5T 2S8, Canada

e-mail: david.wong@uhn.ca

\section{A. J. Yee, BSc}

Department of Kinesiology, McMaster University, Hamilton,

ON, Canada

\section{S. M. Leong, MBBS}

Department of Anesthesia, National University Health System,

Singapore, Singapore

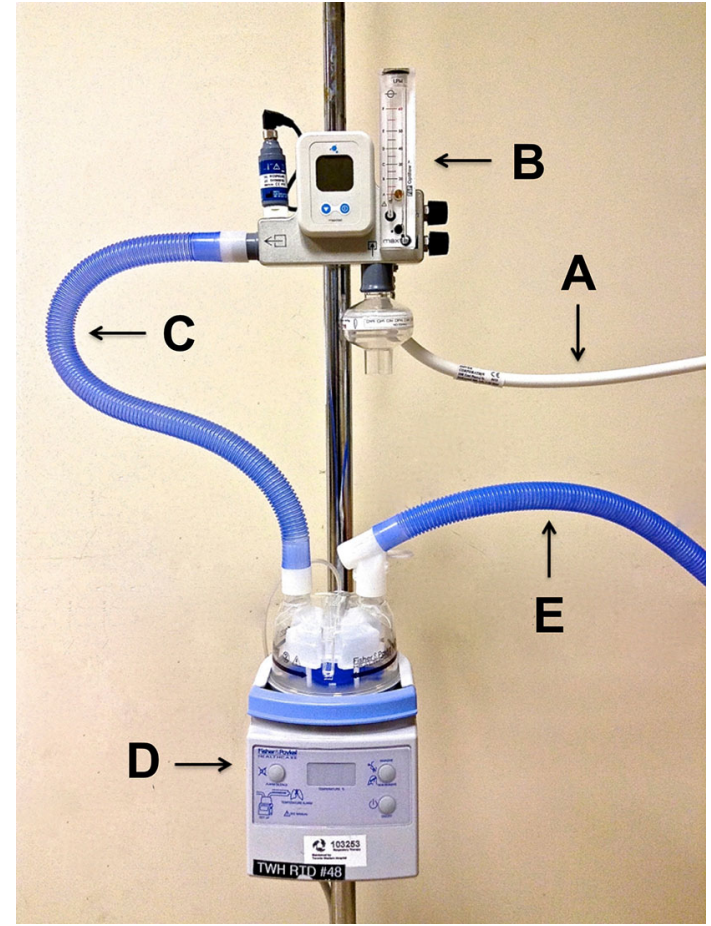

Fig. 3 High-flow nasal cannula system: Optiflow ${ }^{\mathrm{TM}}$ (A) Oxygen is supplied through a high-pressure tube connected to a wall oxygen source. (B) Oxygen and entrained room air enter the blender, mixing the two to achieve the desired $\mathrm{F}_{\mathrm{i}} \mathrm{O}_{2}$ and flow rate. (C) The oxygen mixture flows from the blender to the humidifier. (D) The oxygen mixture is humidified to the desired temperature and humidity level. (E) The humidified oxygen mixture flows from the humidifier to the nasal prongs 